\title{
Detection of human cytomegalovirus antigenaemia: a rapid diagnostic technique for predicting cytomegalovirus infection/ pneumonitis in lung and heart transplant recipients
}

J J Egan, L Barber, J Lomax, A Fox, N Yonan, A N Rahman, C S Campbell, A K Deiraniya, K B Carroll, J Craske, A Turner, A A Woodcock

North West Lung

Centre

J J Egan

K B Carroll

A A Woodcock

Cardiothoracic

Surgery

N Yonan

A N Rahman

C S Campbell

A K Deiraniya

Wythenshawe

Hospital, Manchester

M23 9LT, UK

Public Health

Laboratory,

Withington Hospital,

Manchester, UK

L Barber

J Lomax

A Fox

J Craske

A Turner

Reprint requests to: Dr J J Egan.

Received 7 April 1994 Returned to authors

12 July 1994

Revised version received

4 August 1994

Accepted for publication

10 August 1994

\begin{abstract}
Background - New rapid diagnostic techniques offer the opportunity of early diagnosis of human cytomegalovirus (CMV) infection in immunocompromised patients at risk of developing $\mathrm{CMV}$ disease. The use of human CMV antigenaemia as a predictor of clinical CMV infection and disease in lung and heart transplant recipients was studied prospectively.
\end{abstract}

Methods - Twenty three heart and nine lung transplant recipients who survived $\mathbf{4 0}$ days were observed by standard CMV surveillance with serological testing, culture, and by sequential testing for CMV antigenaemia. CMV antigenaemia testing is a rapid and quantifiable technique in which a viral lower matrix protein is detected in cytospin preparations of peripheral blood polymorphonuclear leucocytes (PMNLs) by immunofluorescent staining.

Results - Eleven patients developed CMV infection and five developed CMV disease (four pneumonitis, one duodenitis). These clinical events occurred at a median of 65 days following transplantation. CMV antigenaemia occurred in 17 patients at a median of 35 days following transplantation. Detection of CMV antigenaemia had a sensitivity of $100 \%$, a specificity of $93.7 \%$, and a positive predictive value of $94 \cdot 1 \%$ for CMV related illness. CMV antigenaemia was positive at a significant interval before the clinical event. High levels of CMV antigenaemia (>50 CMV antigen positive cells $/ 2 \times 10^{5} \mathrm{PMNLs}$ ) occurred in 11 patients and five of these developed disease. CMV antigenaemia of $>50 \mathrm{CMV}$ antigen positive cells $/ 2 \times 10^{5}$ PMNLs had a positive predictive value of $45 \cdot 5 \%$ for disease but a negative predictive value of $100 \%$. Patients with disease had higher levels of antigenaemia than those without disease.

Conclusions -CMV antigenaemia is a rapid diagnostic technique which can identify patients likely to develop CMV disease, potentially allowing early treatment.

(Thorax 1995;50:9-13)

Keywords: cytomegalovirus, heart transplantation, lung transplantation.

Human cytomegalovirus (CMV) infection causes significant morbidity and mortality in lung and heart transplant recipients. In addition to the direct effects of infection such as CMV pneumonitis, the infection is also associated with direct immunopathological effects including superinfection from bacterial and fungal organisms, ${ }^{1}$ graft rejection and failure,${ }^{23}$ and possibly obliterative bronchiolitis. ${ }^{4}$ These serious problems have prompted the use of antiviral prophylaxis in both lung ${ }^{5}$ and heart ${ }^{6}$ transplant recipients, but with questionable advantage because of the high cost and the morbidity of current prophylactic regimens and because the benefit is not yet substantial. ${ }^{67}$ The clinical problems caused by CMV infection are compounded by the fact that the standard diagnostic techniques of serology and culture often allow only a retrospective diagnosis to be made, prompting the need for histological confirmation of CMV disease. New rapid diagnostic techniques might allow the clinician to predict which patients are at greatest risk from $\mathrm{CMV}$, allowing early targeted treatment. CMV antigenaemia testing, which involves the detection of CMV lower matrix phosphoprotein in peripheral blood polymorphonuclear leucocytes (PMNLs) using a monoclonal antibody, is one such technique and has the advantage of being rapid and quantifiable. ${ }^{89}$ The purpose of this study was to assess the feasibility and clinical utility of serial monitoring of CMV antigenaemia for predicting illness and pneumonitis in thoracic transplant recipients. 
Table 1 Diseaseloperation profile of patients $(n=32)$

\begin{tabular}{lll}
\hline No. of patients & Disease & Operation \\
\hline 11 & $\begin{array}{l}\text { Ischaemic heart } \\
\text { disease }\end{array}$ & HTX \\
9 & $\begin{array}{l}\text { Congestive } \\
\text { cardiomyopathy }\end{array}$ & HTX \\
& Valvular heart disease & HTX \\
3 & Bronchiectasis & HLTX \\
1 & Cystic fibrosis & DL \\
3 & Emphysema & SL \\
2 & Fibrosing alveolitis & SL \\
1 & Eisenmenger's & HLTX \\
\hline
\end{tabular}

HTX = heart transplantation; $\mathrm{DL}=$ double lung transplantation; $\mathrm{SL}=$ single lung transplantation; HLTX = heart/lung transplantation.

\section{Methods}

PATIENTS

Thirty eight patients received thoracic allografts between December 1992 and August 1993 of whom six died (three haemorrhage, two graft failure, one graft failure and sepsis) in the early postoperative phase. Thirty two who survived for more than 40 days were included in the study. Signed informed consent was obtained. Twenty three patients underwent cardiac transplantation and nine underwent lung transplantation for end stage respiratory disease (table 1). All patients received intravenous methylprednisolone and azathioprine $4 \mathrm{mg} / \mathrm{kg}$ as induction immunosuppression. In addition, all heart recipients, heart-lung recipients, and one single lung recipient ( 26 of the 32 patients) received rabbit antithymocyte globulin, $1 \mathrm{mg} / \mathrm{kg}$ for three days, for induction of immunosuppression. For maintenance immunosuppression all received cyclosporin, azathioprine $2 \mathrm{mg} / \mathrm{kg}$, and prednisolone.

Cardiac graft surveillance was undertaken by myocardial biopsy at weekly intervals for six weeks and two-weekly until three months. Graft rejection was graded according to international classification. ${ }^{10}$

\section{ROUTINE CMV SURVEILLANCE}

The CMV antibody status of the organ donor and recipient was determined before transplantation (CMV scan; Becton Dickenson). Postoperative CMV surveillance involved routine virus culture and serological examination. Throat swabs and urine were inoculated onto human embryonic fibroblasts and examined for cytopathic effect. CMV specific IgG and IgM antibody were detected by enzyme immunoassay. ${ }^{11}$ Surveillance specimens were collected on the first postoperative day and then weekly for six weeks, two-weekly until week 12, and monthly thereafter.

All nine lung transplant recipients uncierwent surveillance bronchoscopy, bronchoalveolar lavage, and transbronchial biopsy routinely at one, two, and three months following surgery and also if unexplained symptoms, signs, or a change in spirometric parameters occurred. Bronchoscopy, transbronchial biopsy, and bronchoalveolar lavage were undertaken in 10 of 24 heart transplant recipients for possible CMV pneumonitis. Bronchoalveolar lavage specimens were examined for CMV by the detection of early antigen fluorescent foci (DEAFF test) using a monoclonal antibody (6A2 anti-immediate early gene product $)^{12}$ in addition to routine culture. All patients with gastric related symptoms underwent endoscopic examination and biopsy.

\section{END POINT DEFINITIONS}

Patients were assigned to categories of CMV "asymptomatic infection", "symptomatic infection", or "disease" on the following criteria:

1. Asymptomatic CMV infection was defined as a positive culture for CMV from a nonperipheral site (bronchoalveolar lavage), a positive IgM antibody result (>4 units IgM), or both.

2. Symptomatic CMV infection was defined as unexplained pyrexia with or without a $50 \%$ fall in the white cell count, or a 2.5 fold increase in serum transaminases (in the absence of histological evidence of hepatitis) in the presence of a positive IgM result ( $>4$ units IgM) and/or a positive bronchoalveolar lavage DEAFF test, or both.

3. Human CMV disease was defined as histological evidence of end organ damage caused by the virus.

\section{ANTIGENAEMIA}

EDTA blood samples $(5 \mathrm{ml})$ for detection of CMV antigenaemia were collected at the time of routine CMV surveillance and rapidly transported to the virology laboratory. Samples which did not reach the laboratory within five hours were considered unsuitable. Cytospin preparations of dextran enriched PMNLs were obtained, and incubated with the monoclonal antibody (mouse monoclonal antibody IC3 anti-CMV pk 65, Biosoft, TCS Biologicals Ltd, Boltolph Claydon, Bucks, UK) followed by immunofluorescence staining, and the number of antigen positive cells per 200000 PMNLs counted using fluorescence microscopy ${ }^{13}$ (fig 1). A level of $>50$ antigen positive cells $/ 200000$ PMNLs was considered to be "high level" antigenaemia.

\section{DRUG TREATMENT}

Antiviral therapy was administered only after an end point clinical definition had been reached, with the exception of two patients at high risk of developing disease who received ganciclovir because of high levels of antigenaemia associated with pyrexia. The drug schedule for ganciclovir was $5 \mathrm{mg} / \mathrm{kg} 12$ hourly for 21 days in the presence of CMV disease or at the discretion of the clinician for symptomatic infection.

\section{STATISTICAL ANALYSIS}

Only CMV antigenaemia levels before the occurrence of a clinical end point or before ganciclovir was administered were used in the analysis. Differences in the antigenaemia levels between groups were analysed by the MannWhitney $U$ test. The differences between time events were analysed by the Wilcoxon rank test. For all analyses the confidence intervals were set at $95 \%$. Sensitivity, specificity, and predictive values were calculated as detailed elsewhere. ${ }^{14}$ 


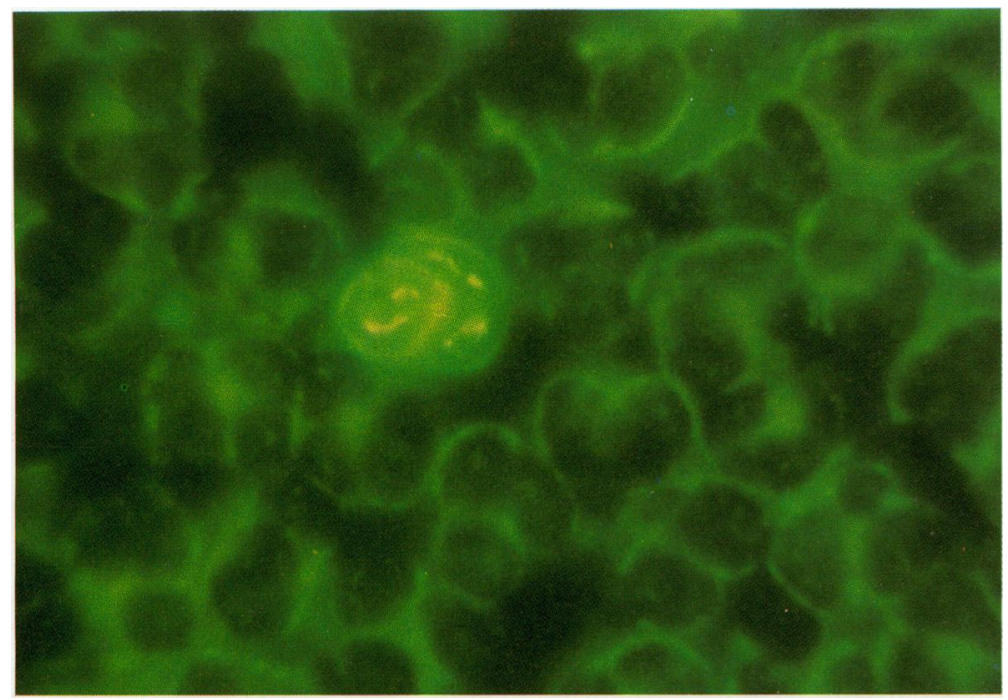

Figure 1 Peripheral blood polymorphonuclear leucocyte stained with a fluorescent labelled monoclonal antibody to cytomegalovirus $65 \mathrm{kDa}$ lower matrix phosphoprotein (human CMV antigenaemia).

Table 2 Human CMV serological status according to transplant and antigen result

\begin{tabular}{lclcc}
\hline Serological status & $\begin{array}{l}\text { Heart } \\
\text { transplant }\end{array}$ & $\begin{array}{l}\text { Lung } \\
\text { transplant }\end{array}$ & $\begin{array}{l}\text { Antigen } \\
\text { positive }\end{array}$ & $\begin{array}{l}\text { Antigen } \\
\text { negative }\end{array}$ \\
\hline D+R+ & 7 & 2 & 9 & 0 \\
D-R- & 9 & 3 & 0 & 12 \\
D+R- & 4 & 0 & 2 & 2 \\
D-R+ & 3 & 4 & 6 & 1 \\
Total & 23 & 9 & 17 & 15 \\
\hline
\end{tabular}

$\mathrm{CMV}=$ cytomegalovirus; $\mathrm{R}=$ recipient; $\mathrm{D}=$ donor; $+=\mathrm{CMV}$ seropositive; $-=\mathrm{CMV}$ seronegative.

\begin{abstract}
Results
Nine patients studied were CMV seropositive recipients $(R+)$ whose donors were CMV seropositive $(\mathrm{D}+)$. Twelve seronegative recipients were matched with seronegative donors $(\mathrm{D}-\mathrm{R}-)$. Four seronegative recipients received grafts from seropositive donors $(\mathrm{D}+\mathrm{R}-)$ and received $\mathrm{CMV}$ hyperimmunoglobulin $100 \mathrm{mg} / \mathrm{kg}$ on days $1,7,14$ 21,28 , and 49 following transplantation. ${ }^{15}$ Seven seropositive recipients had CMV seronegative donors $(\mathrm{D}-\mathrm{R}+$ ) (see table 2 for details).
\end{abstract}

Conventional diagnostic methods for CMV

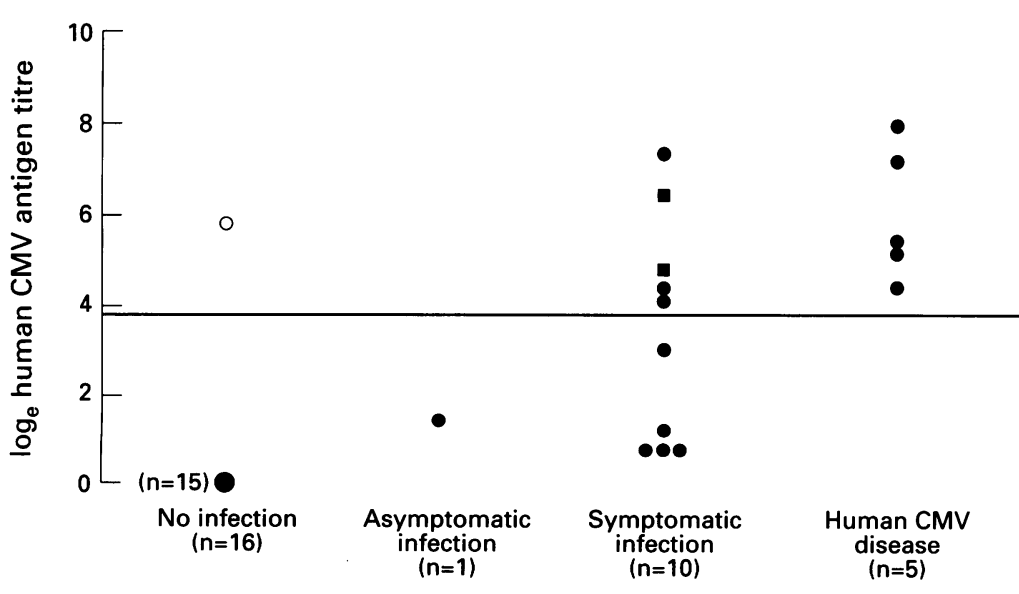

Figure 2 Human CMV antigenaemia in relation to diagnostic group. $\square=$ two patients thought likely to develop the disease who received ganciclovir; $\bigcirc=$ one patient with unexplained fever in whom conventional tests for human CMV were negative. Symbols above the line represent $>50$ human CMV antigen positive cells $/ 2 \times 10^{5}$ polymorphonuclear leucocytes. infection resulted in 16 patients being diagnosed as having CMV related illness (one asymptomatic infection, 10 symptomatic infection, and five disease) and 16 as being free of CMV related illness (fig 2). A clinical diagnosis of CMV related illness was made at a median of 65 days (range 19-142) following transplantation (table 3).

Two of the nine lung transplant recipients developed CMV pneumonitis; the remaining seven showed no histological evidence of the disease. Two heart transplant recipients had histological evidence of pneumonitis. Of the eight other heart recipients who underwent a transbronchial biopsy, one had CMV inclusion bodies but no pneumonitis (patient 17), and one had a positive bronchoalveolar lavage DEAFF test (patient 2); the remainder showed no evidence of CMV. Three patients who underwent endoscopy and gastric biopsy showed no evidence of CMV gastritis. No patient underwent liver biopsy.

Seventeen patients developed CMV antigenaemia at a median of 35 days (range 13-93) following transplantation (table 3 ). This included all 16 patients with conventionally diagnosed CMV illness and one patient (patient 1) with no clinical evidence of CMV illness by conventional testing (table 4 ) but who developed an otherwise unexplained pyrexia. The remaining 15 patients had negative CMV antigenaemia and none of these developed CMV related illness (fig 2).

Twelve of the $15 \mathrm{CMV}$ antigen negative patients were $\mathrm{D}-\mathrm{R}-$ (table 2 ). The remaining three were "high risk" patients; two $\mathrm{D}+\mathrm{R}-$ heart transplant recipients who received immunoglobulin prophylaxis and one $\mathrm{D}-\mathrm{R}+$ lung transplant recipient who received no prophylaxis (table 2).

CMV antigenaemia was detected at a time ( $n=17$, median 35 days, range 13-93) significantly before a clinical event related to CMV occurred $(n=16$, median 65 days, range 19142) (median difference $=28$ days, $p<0.005$ ). CMV antigenaemia was also positive before a response in IgM serology $(n=13$, median 64 days, range 28-167) (median difference $=30$ days, $\mathrm{p}<0 \cdot 01$ ).

In this study CMV antigenaemia had a sensitivity of $100 \%$ and a specificity of $93.7 \%$ for infection, with a positive predictive value for CMV infection of $94 \cdot 1 \%$

Eleven patients developed high level antigenaemia (>50 positive antigen cells $/ 2 \times 10^{5}$ PMNLs). Of these five had CMV disease, five had symptomatic infection, and one did not have CMV illness by the conventional definitions (table 4). High level CMV antigenaemia was detected at a median of 14 days (range 2-44) before the onset of disease (four pneumonitis, one duodenitis).

The CMV antigenaemia levels were significantly higher in the five patients with disease (median $=200$ cells $/ 2 \times 10^{5}$ PMNLs, range 73-2647) than in the 27 patients without disease (median $=0$ cells $/ 2 \times 10^{5}$ PMNLs, range 0-1386) (median difference $=200$ cells, $\mathrm{p}<0.005$ ). The five patients with disease also had significantly higher levels of antigenaemia 
Table 3 Time frame of antigen positive patients

\begin{tabular}{|c|c|c|c|c|c|}
\hline Patients & Operation & Clinical definitions & $\begin{array}{l}\text { Days to } \\
\text { antigen }\end{array}$ & $\begin{array}{l}\text { Days to } \\
\text { clinical event }\end{array}$ & $\begin{array}{l}\text { Days to } \\
\text { IgM change }\end{array}$ \\
\hline 1 & HTX & No infection & 33 & No event & Negative \\
\hline 2 & HTX & Asymptomatic infection & 59 & 104 & Negative \\
\hline 3 & HTX & Symptomatic infection & 61 & 89 & 167 \\
\hline 4 & HTX & Symptomatic infection & 19 & 19 & 33 \\
\hline 5 & HTX & Symptomatic infection & 21 & 25 & 28 \\
\hline 6 & HTX & Symptomatic infection & 18 & 46 & 60 \\
\hline 7 & HTX & Symptomatic infection & 93 & 142 & 121 \\
\hline 8 & HTX & Symptomatic infection & 13 & 66 & 80 \\
\hline 9 & HTX & Symptomatic infection & 16 & 51 & 69 \\
\hline 10 & HLTX & Symptomatic infection & 58 & 70 & 49 \\
\hline 11 & SL & Symptomatic infection & 34 & 78 & Negative \\
\hline 12 & SL & Symptomatic infection & 35 & 105 & Negative \\
\hline 13 & SL & Pneumonitis & 65 & 54 & 118 \\
\hline 14 & SL & Pneumonitis & 50 & 83 & 93 \\
\hline 15 & HTX & Pneumonitis & 29 & 58 & 36 \\
\hline 16 & HTX & Pneumonitis & 50 & 64 & 64 \\
\hline 17 & HTX & Duodenitis & 48 & 39 & 41 \\
\hline
\end{tabular}

HTX = heart transplantation; SL = single lung transplantation; HLTX = heart/lung transplantation.

than the 12 antigen positive patients without disease (median $=35$ cells $/ 2 \times 10^{5}$ PMNLs, range $1-1386$ ) (median difference $=151$ cells, $\mathrm{p}<0.05)$.

The positive predictive value for CMV disease with an antigen count of $>50$ positive cells/ $2 \times 10^{5}$ PMNLs was $45.5 \%$ and the negative predictive value was $100 \%$.

Three CMV antigen positive patients died during the study period; patient 2 from pancreatitis and Pneumocystis carinii pneumonia on day 110 , patient 15 from acute cholecystitis and septicaemia at 86 days, and patient 17 as a result of graft failure, pancreatitis, and CMV duodenitis 57 days after transplantation.

\section{Discussion}

In immunocompromised transplant recipients the diagnosis of human CMV infection and disease using conventional diagnostic techniques is often difficult. Recent advances in viral diagnostic techniques have made rapid early diagnosis of CMV infection possible. The importance of early diagnosis is emphasised by the increasing administration of prophylactic antiviral therapy in different transplantation populations ${ }^{5616}$ against the background of the emergence of ganciclovir-resistant CMV strains. ${ }^{1718}$

The detection of human CMV antigenaemia in peripheral blood PMNLs is a rapid and quantifiable technique that has been used for the monitoring of CMV infection in heart trans-

Table 4 Serological results, infection, and quantity of antigenaemia

\begin{tabular}{llll}
\hline Patients & Serology & Clinical events & $\begin{array}{l}\text { Positive cells (no/2 } \times 10^{5} \\
\text { neutrohils) }\end{array}$ \\
\hline 1 & D+R+ & No infection & 338 (pyrexia) \\
2 & D+R+ & Asymptomatic infection & 3 \\
3 & D+R- & Symptomatic infection & 111 (ganciclovir) \\
4 & D+R+ & Symptomatic infection & 18 \\
5 & D+R+ & Symptomatic infection & 53 \\
6 & D-R+ & Symptomatic infection & 68 \\
7 & D+R+ & Symptomatic infection & 558 (ganciclovir) \\
8 & D-R+ & Symptomatic infection & 1386 \\
9 & D-R+ & Symptomatic infection & 1 \\
10 & D-R+ & Symptomatic infection & 1 \\
11 & D-R+ & Symptomatic infection & 2 \\
12 & D+R+ & Symptomatic infection & 1 \\
13 & D+R+ & Pneumonitis & 73 \\
14 & D-R+ & Pneumonitis & 200 \\
15 & D+R+ & Pneumonitis & 152 \\
16 & D+R+ & Pneumonitis & 2647 \\
17 & D + R & Duodenitis & 1200 \\
\hline
\end{tabular}

$\mathrm{D}=$ donor; $\mathrm{R}=$ recipient; $+=\mathrm{CMV}$ seropositive; $-=\mathrm{CMV}$ seronegative. plant recipients ${ }^{89}$ and for the early diagnosis of CMV infection in renal transplant recipients. ${ }^{19}$

In our patients CMV antigenaemia had a sensitivity of $100 \%$ and a specificity of $93.7 \%$ for infection as defined by conventional diagnostic techniques (CMV specific IgM, positive bronchoalveolar lavage DEAFF test). One patient (patient 1, table 4) with pyrexia in association with peripheral blood antigenaemia was not defined as having a CMV related event as he failed to demonstrate evidence of infection using conventional diagnostic techniques. In view of the strict end point definitions we may have underestimated the specificity of CMV antigenaemia.

In addition to high sensitivity and specificity for CMV infection, antigenaemia offers two further advantages. Firstly, it occurs significantly before the onset of clinical symptoms and serological changes. Secondly, measurement of levels of antigenaemia may allow the clinician to predict patients most likely to develop CMV disease.

Invasive diagnostic techniques are currently needed to confirm or exclude CMV disease, but quantifiable techniques such as CMV antigenaemia could allow clinicians to be more selective as to which patients are subjected to biopsy or treated blind with antiviral therapy. High level antigenaemia (>50 cells $/ 2 \times 10^{5}$ PMNLs) had a positive predictive value of $45 \%$ and a negative predictive value of $100 \%$. The importance of the high negative predictive value is emphasised by the absence of CMV antigenaemia in two seronegative heart transplant recipients whose donors were seropositive and one seropositive lung recipient whose donor was seronegative (table 2). These three patients were at high risk of developing CMV related illness and the heart transplant recipients received immunoglobulin prophylaxis. As neither of the heart recipients subsequently developed CMV infection it is possible that the donor serological results may have been falsely positive. The clinical application of CMV antigenaemia in these cases would have allowed the antiviral therapy to be withheld in the absence of viraemia, thereby reducing drug costs and morbidity.

The early administration of targeted antiviral therapy in the presence of CMV antigenaemia may obviate the need for expensive blanket 
prophylactic regimens, provided this can be shown to mitigate effects of the disease. Two of the six patients with high level antigenaemia who did not develop CMV disease (patients 3 and 7 , table 4) were considered to be high risk patients and, as a result, received ganciclovir when high level antigenaemia was detected in association with a pyrexia. Patient 3 was a CMV mismatch $\mathrm{D}+\mathrm{R}$ - who became antigen positive despite receiving hyperimmunoglobulin and patient 7 had life threatening cardiac rejection. Despite the high level of antigenaemia, neither of these patients went on to develop CMV disease following the administration of gangiclovir. We suspect that, in the absence of specific antiviral therapy, these two patients would have developed CMV disease resulting in increased positive predictive values and higher specificity of "high level" antigenaemia for diagnosing disease.

High level antigenaemia should be interpreted against the background of the donor and recipient serological results. In a further two of the six patients with high level antigenaemia but no CMV disease (patients 6 and 8 , table 4) the donors were seronegative suggesting that the viraemia may have represented reactivation of "endogenous" recipient virus with a resulting milder infection. ${ }^{20}$

When evaluating the published literature on CMV in transplant recipients it is difficult to compare different transplant programmes because of differing immunosuppression regimens and the use of various definitions as to what constitutes $\mathrm{CMV}$ infection or disease. ${ }^{21}$ We therefore used an aggressive policy of acquiring tissue for confirmation of disease. Nineteen of the 32 patients ( 10 of the 23 heart transplant recipients and all of the lung recipients) had transbronchial biopsies to validate clearly either CMV disease or symptomatic infection. As the antigenaemia is quantitative and has high sensitivity and specificity, it may provide a new standard for definitions of CMV related illness. Furthermore, its application could provide a useful end point in multicentre studies of CMV prophylaxis where variability of immunosuppressive regimens occurs.

A major practical difficulty with this diagnostic technique is the recommendation that EDTA samples need to be in the laboratory within three hours for cytospin preparation to obtain peripheral blood PMNLs suitable for immunofluorescent staining. This necessitated a dedicated transport service to deliver samples to an offsite virology laboratory.

Human CMV antigenaemia detection is a technique which can be applied in lung and heart transplant recipients to predict clinical illness and could allow clinicians to identify rapidly patients who may require specific early antiviral treatment. In an asymptomatic patient high level antigenaemia should prompt invasive investigations to acquire tissue for histological assessment. Furthermore, high level antigenaemia should be interpreted against the clinical background of serological test results and level of immunosuppression. The preventative effects of early targeted antiviral treatment for asymptomatic patients with high levels of antigenaemia needs further evaluation. Antigenaemia also promises to redefine current diagnostic definitions for $\mathrm{CMV}$ infection and may ultimately dispense with the need for histological confirmation of the disease.

JE is supported by the Lancardis Foundation. The authors are grateful to the Wellcome Foundation, Crewe Hall, Crewe for their financial support towards this study (LB) and Sister Ruth Martyszczuk for her help in organising the transport of EDTA samples. They also acknowledge the contribution of the "New samples. They also acknowledge the contribution of the "New
Heart, New Start" appeal and Julie Morris MSc for her advice on the statistical methods.

1 Smyth RL, Scott JP, Borysiewicz LK, Sharples LD, Stewart $\mathrm{S}$, Wreghitt TG, et al. Cytomegalovirus infection in heart/ lung transplants: risk factors, clinical associations, re-
sponse and treatment. $\mathscr{f}$ Infect Dis 1991;164:1045-50.

2 Gratten MT, Morenocabral CE, Starnes VA, Oyer PE, Stinson FB, Shumway NE. Cytomegalovirus infection is associated with cardiac rejection and atherosclerosis. is associated with cardiac

3 McDonald K, Rector TS, Braulin EA, Kubo SH, Olivar MT. Association of coronary artery disease in cardiac transplant recipients with cytomegalovirus infection. $\mathrm{Am}$ f Candiol 1989;64:359-62.

4 Duncan SR, Paradis IL, Yousem SA, Similo SL, Grgurich WF, Williams PA, et al. Sequelae of cytomegalovirus pulmonary infections in lung allograft recipients. Am Rev Respir Dis 1992;146:1419-25.

5 Duncan SR, Paradis IL, Dauber JH, Yousem SA, Hardesty RL, Griffiths BP. Ganciclovir prophylaxis for cytomegalovirus infection in pulmonary allograft recipients. Am Rev Respir Dis 1992;146:1213-5.

6 Merigan TC, Renlund DG, Keay S, Bristow MR, Starnes $\mathrm{V}$, O'Connell et al. A controlled trial of ganciclovir to prevent cytomegalovirus disease after heart transplantation. N Engl f Med 1992;326:1182-6.

7 Bailey TC, Trulock EP, Ettinger NA, Storch GA, Cooper JD, Powderly WG. Failure of prophylactic ganciclovir to prevent cytomegalovirus disease in recipients of lung to prevent cytomegalovirus disease in recipic

8 The TH, van der Big W, van den Berg AP, van der Giessen, Weits J, Sprenger HG. Cytomegalovirus antigenaemia. Rev Infect Dis 1990;12: s737-44.

9 Gerna G, Zipeto D, Parea M, Revello MG, Silini E, Percivalle E, et al. Monitoring of human cytomegalovirus infections and ganciclovir treatment in heart transplan recipients by determination of viraemia, antigenaemia, and DNAemia. $\mathcal{F}$ Infect Dis 1991;164:488-98.

10 Billingham ME, Carey NRB, Hammond ME, Kemnitz J, Marboe C, McCallister HA, et al. A working formulation for the standardization of nomenclature in the diagnosis of heart and lung rejection: Heart Rejection Study Group. of heart and lung rejection: Heart Rej

11 Morris DJ, Fox AJ, Grint PCA, Bell EJ, Lomax J, McCartney RA. Cytomegalovirus, varicella zoster and coxsacki $B$ virus specific IgM antibody response in children with cancer. Serodiagn Immunother Infect Dis 1990;4:115-20.

12 Morris DJ, Lomax J, Craske J, Longson M, Fox AJ. Effects of centrifugal enhancement of infectivity on the rapid detection of human cytomegalovirus in cell culture by detection of human cytomegalovirus in cell culture by mediate early nuclear antigen. Serodiagn Immunother Infect Dis $1987 ; 1: 141-52$.

13 Gerna G, Revello MG, Percivalle E, Morini F. Comparison of different immunostaining techniques and monoclonal antibodies to the lower matrix phosphoprotein (pp65) for optimal quantitation of human cytomegalovirus antigenaemia. F Clin Microbiol 1992;30:1232-7.

14 Vecchio TJ. Predicted value of a single diagnostic test in unselected populations. $N$ Engl f Med 1966;274:1171-3.

15 Freeman R, Gould FK, McMaster A. Management of cytomegalovirus antibody negative patients undergoing heart megalovirus antibody negative patients under
transplantation. $\mathcal{F}$ Clin Pathol 1990;43:373-6.

16 Schmidt GM, Horak DA, Niland JC, Duncan SR, Forman SJ, Zaia JA, et al. A randomised controlled trial of prophylactic ganciclovir for cytomegalovirus pulmonary infection in recipients of allogenic bone marrow transplants. $N$ Engl f Med 1991;324:1005-11.

17 Erice A, Chou S, Biron KK, Stanat SC, Balfour HH Jr, Jordan MC. Progressive disease due to ganciclovir-resistant cytomegalovirus in immunocompromised patients. $N$ Engl f Med 1989;320:289-93.

18 Drew WL, Miner RC, Busch DF, Follansbee SE, Gullett J, Mehalko SG, et al. Prevalence of resistance in patients receiving ganciclovir for serious cytomegalovirus infection. F Infect Dis 1991;163:716-9.

19 Klauser R, Kotzmann H, Wamser P, Braza P, Popov-Kraupp $T$, Franz $M$, et al. Is determination of PP 65 useful for early diagnosis of cytomegalovirus infection in renal transplant recipients. Transplant Proc 1992;24:2628-30.

20 Grundy JE, Lui SF, Super M, Berry NJ, Sweny P, Fernando $\mathrm{ON}$, et al. Symptomatic cytomegalovirus infection in seropositive kidney recipients; reinfection with donor virus rather than reactivation of recipient virus. Lancet 1988;ii: $132-5$.

21 Ettinger NA, Bailey TC, Trulock EP, Storch GA, Anderson $\mathrm{D}$, Raab S, et al. Cytomegalovirus infection and pneumonitis: impact after isolated lung transplantation. $\mathrm{Am}$ Rev Respir Dis 1993;147:1017-23. 